\title{
PENGARUH PENGGUNAAN MULTIMEDIA INTERAKTIF TERHADAP HASIL BELAJAR INTERAKSI MANUSIA DAN KOMPUTER DI UNIVERSITAS HAMZANWADI
}

\author{
Ahmad Fathoni \\ Program Studi Pendidikan Informatika, \\ Fakultas Keguruan dan Ilmu Pendidikan, Universitas Hamzanwadi \\ e-mail: ahmad.fathonis2ptk@ gmail.com ${ }^{1}$
}

\begin{abstract}
Abstrak
Tujuan pada penelitian ini adalah untuk mendeskripsikan dan menganalisis pengaruh media pembelajaran berbasis multimedia interaktif terhadap hasil belajar matakuliah Interaksi Manusia dan Komputer (IMK). Penelitian ini merupakan penelitian survey dengan pendekatan kuantitatif berjenis penelitian survei. Populasi dan sampel pada penelitian ini adalah seluruh mahasiswa semester III diantaranya adalah kelas IIIA dan IIIB yang berjumlah 50 mahasiswa. Instrumen yang digunakan untuk mengumpulkan data adalah berupa angket. Metode yang digunakan untuk analisis data pada penelitian ini adalah statistik deskriptif. Hasil penelitian ini menunjukan bahwa variabel $\mathrm{X}$, dan $\mathrm{Y}$ mendekati kategori tinggi dengan nilai persentase secara berurutan $71,72 \%$, dan $75 \%$. Penerapan media pembelajaran berbasis multimedia interaktif di perguruan tinggi merupakan salah satu solusi untuk menciptakan pembelajaran yang menarik, inovatif, menantang dan dapat berfikir secara mandiri.
\end{abstract}

Kata Kunci : Media Pembelajaran, Multimedia Interaktif, Hasil Belajar.

\begin{abstract}
The aims of this research were to describe and analyze the influence of interactive multimedia-based learning media toward learning outcome of computer human interaction (HCI) course. This research is a survey research with quantitative approach to a research survey. The population and sample in this research is the entire semester III students among them is a class $I I I^{A}$ and $I I I^{B}$ totaling 50 students. The instrument of data collecting in this research is a questioner. The method used for data analysis in this research is descriptive statistics. The results of this research show that the variables $X$ and $Y$ approach the high category with the percentage of successively $71.72 \%$, and $75 \%$. The application of interactive multimedia-based learning media in various learning is one of the solutions to create interesting, innovative, challenging and able to think independently.
\end{abstract}

Keywords: Learning Media, Interactive Multimedia, Learning Outcomes.

\section{PENDAHULUAN}

Pendidikan memiliki peran yang sangat penting dalam rangka membangun bangsa. Oleh karena itu hal-hal yang menyangkut pendidikan telah ditetapkan dalam berbagai peraturan dan perundang-undangan, diantaranya dalam undang-undang sistem pendidikan nasional Nomor 20 Tahun 2009 bahwa : Pendidikan nasional berfungsi mengembangkan kemampuan dan membentuk watak serta peradaban bangsa bertujuan untuk berkembangnya potensi peserta didik agar menjadi manusia yang beriman dan bertaqwa kepada Tuhan Yanga Maha Esa, berakhlak mulia, sehat, berilmu, cakap, kreatif mandiri dan menjadi warga Negara yang demokratis serta bertanggung jawab. 
e-ISSN 2549-7472

Volume 1, Nomor 1, Juni 2017

Berbagai konsep dan wawasan baru tentang proses belajar mengajar telah muncul dan berkembang seiring dengan pesatnya ilmu pengetahuan dan teknologi. Usaha tersebut diantaranya pembaharuan dan perubahan kurikulum. Salah satu upaya yang dilakukan bangsa Indonesia saat ini. Kurikulum yang ada saat ini berpusat pada mahasiswa. Mahasiswa harus mampu untuk belajar sendiri dan berfikir kritis.

Sekarang ini pertumbuhan teknologi semakin pesat. Hal ini dapat dilihat dari berbagai macam produk yang semakin canggih. Seperti hal dalam pemberian pembelajaran terhadap mahasiswa. Pembelajaran yang diterapkan berbantuan komputer dan ditampilkan menggunakan proyektor. Pada umumnya bahwa model pembelajaran sangat beragam namun dalam penerapannya tergantung pada kebutuhan dan disesuaikan dengan materi, media pembelajaran dan kemampuan pengajar itu sendiri.

Salah satu alternatif pemebelajaran yang dapat membantu mahasiswa untuk melakukan banyak eksplorasi dalam waktu yang terbatas adalah dengan menggunakan bantuan komputer dengan berbagai program yang relevan. Penggunaan komputer sebagai media pengajaran dikenal dengan nama pengajaran dengan bantuan komputer atau Computer-Assisted Instruction (CAI). Salah satu aplikasi CAI dalam dunia pendidikan adalah Multimedia Pembelajaran Interaktif atau CD pembelajaran interaktif. Karena pembelajaran juga tidak lepas dari aspek teknologi.

Idealnya proses pembelajaran bukan lagi sebagai proses transfer ilmu dari dosen ke mahasiswa. Melainkan pembelajaran yang lebih diartikan sebagai upaya aktif dosen untuk membantu mahasiswa dalam membangun pengetahuannya dengan menggunakan pengalaman atau pengetahuan yang telah dimiliki mahasiswa tersebut. Dosen tidak lagi berposisi sebagai pentrasfer pengetahuan kepada mahasiswa, melainkan sebagai pasilitator yang memberikan kesempatan kepada mahasiswa untuk membangun pengetahuannya melalui berbagai aktivitas pembelajaran yang bermakna. Maka dengan menggunakan Multimedia pembelajaran interaktif harapannya mahasiswa akan lebih mudah membangun pengetahuan dalam pembelajaran interaksi mausia dan komputer (IMK), karena media yang dipergunakan menggunakan contoh nyata dari kehidupan sehari-hari.

Berdasarkan wawancara dengan dosen IMK di Prodi Pendidikan Informatika Universitas Hamzanwadi Selong semester III (tiga) pada matakuliah IMK, terdapat beberapa keterbatasan mahasiswa dalam memahami materi pembelajaran saat proses pembelajaran berlangsung. Karena pelaksanaan pembelajaran selama perkuliahan IMK masih berpusat pada dosen dan mahasiswa cendrung menjadikan mahasiswa pasif yang seharusnya dapat aktifter libat dalam pembelajaran. Semua permasalahan yang ada berimbas terhadap rendahnya hasil belajar mahasiswak husunya pada pengenalan materi perangkat hardware yang terlihat pada hasil perkuliahan tahun ajaran 2016 dan 2017.

Dari nilai hasil belajar matakuliah IMK di tahun 2016 dan tahun 2017 terlihat penurunan hasil belajar mahasiswa. Salah satu penyebabnya karena kurang penggunaann media pembelajaran, pada tahun 2016 dalam perkuliahan IMK menggunakan media power point yang penggunaannya belum optimal. Sedangkan ditahun 2017 digunakanya media multimedia interaktif yang lebih kompels yaitu menggunakan macromedia flash dalam dalam pembuatan media pembelajaran. Kemudian tanpa digunakanya media pada matakuliah IMK mahasiswa merasa sulit memahami materi perkuliahan sebab tidak dapat mengkontekstualkan dan mengintegrasikan pembelajaran IMK secara nyata.

Mengatasi permasalahan di atas maka dilakukan studi pendahuluan yang diperoleh informasi bahwa memang keterbatasan cara penyampaain materi dengan cara ceramah dan atau penggunaan media penunjukan gambar menyebakan tidak adanya atau rendahnya pemahaman terhadap materi matakuliah yang diajarkan. Berdasarkan uraian permasalahan

EDUMATIC: Jurnal Pendidikan Informatika | 30 
tersebut, penelitian ini dilakukan dengan tujuan utama memperoleh bukti pengaruh media pembelajaran berbasis multimedia interaktif terhadap proses pembelajaran. Dimana multimedia interaktif yang diajarkan dosen menggunakan multimedia pembelajaran interaktif. Multimedia Pembelajaran interaktif yang dibua tjuga harus maksimal, mudah digunakan dan dapat menarik perhatian pengguna untuk diakses. Pembuatan multimedia pembelajaran interaktif bisa melalui Microsoft office power point, Adobe Macromedia Flash, Prezi, Lectora, dan penyedia materi secara online. Multimedia pembelajaran interaktif di penelitian ini menggunakan Adobe Macromedia Flash.

\section{METODE PENELITIAN}

Penelitian termasuk penelitian kuantitatif jenis survei. Penelitian dilakukan dikampus Universitas Hamzanwadi Pancor. Populasi yang digunakan adalah semua mahasiswa prodi pendidikan informatika semester III sejumlah 46 Mahasiswa. Pengambilan sampel menggunakan teknik proportionate random sampling. Jumlah sampel total yang diambil menurut tabel penentuan sampel dari Isacd and Michael (Sugiyono, 2014: 87) dengan tingkat kesalahan $5 \%$.

Teknik pengumpulan data menggunakan wawancara, observasi, dokumentasi dan tes (instrumen). Instrumen yang digunakan 25 butir. Semua butir instrumen di uji kevalidannya. Teknikanalisis data dalam penelitian ini menggunakan statistik deskriptif. Mendeskripsikan data digunakan kategorisasi menurut Mardapi (2007: 123). Pembagian empat kategori dimana $\mathrm{x}=$ rata-rata skor keseluruhan mahasiswa prodi pendidikan informatika semester III dalam satu kelas dan $\mathrm{SB}=$ simpangan baku adalah sebagai berikut.

Tabel 1. Pembagian Empat kategori

\begin{tabular}{ll}
\hline \multicolumn{1}{c}{ Skor Siswa } & \multicolumn{1}{c}{$\begin{array}{c}\text { Kategori Sikap dan } \\
\text { Minat }\end{array}$} \\
\hline $\mathrm{X} \geq \overline{\mathrm{X}}+1 . \mathrm{SB}_{\mathrm{x}}$ & Sangat Tinggi \\
$\overline{\mathrm{x}}+1 . \mathrm{SB}_{\mathrm{x}}>\mathrm{X} \geq \overline{\mathrm{X}}$ & Tinggi \\
$\overline{\mathrm{X}}>\mathrm{X} \geq \overline{\mathrm{x}}-1 . \mathrm{SB}_{\mathrm{x}}$ & Rendah \\
$\mathrm{X}<\overline{\mathrm{X}}-1 . \mathrm{SB}_{\mathrm{x}}$ & Sangat Rendah \\
\hline
\end{tabular}

Dalam penelitian ini diuji empat asumsi (Wagiran, 2014), yaitu normalitas, heterokdastisitas, linieritas, dan multikolinieritas. Pengujian hipotesis menggunakan analisis regresi ganda. Sebagai kriteria penerimaan dan penolakan digunakan tingkat signifikansi 5\%. Untuk mengetahui korelasi dan besarnya pengaruh masing-masing variabel bebas terhadap variabel terikat digunakan analisis regresi sederhana.

\section{HASIL DAN PEMBAHASAN}

Hasil perhitungan melalui statistik deskriptif media pembelajaran berbasis multimedia interaktif, hasil belajar disajikan pada tabel 2 dan gambar 1. 
e-ISSN 2549-7472

Volume 1, Nomor 1, Juni 2017

Tabel 2. Distribusi Media Pembelajaran Berbasis Multimedia Interaktif dan Hasil Belajar

\begin{tabular}{cccccc}
\hline No. & Katagori & \multicolumn{2}{c}{ Y } & \multicolumn{2}{c}{ X } \\
\hline $\mathbf{1 .}$ & SangatTinggi & 34 & 18 & 39 & 20 \\
2. & Tinggi & 75 & 39 & 91 & 48 \\
3. & Rendah & 47 & 25 & 42 & 22 \\
4. & SangatRendah & 35 & 18 & 19 & 10 \\
\hline
\end{tabular}

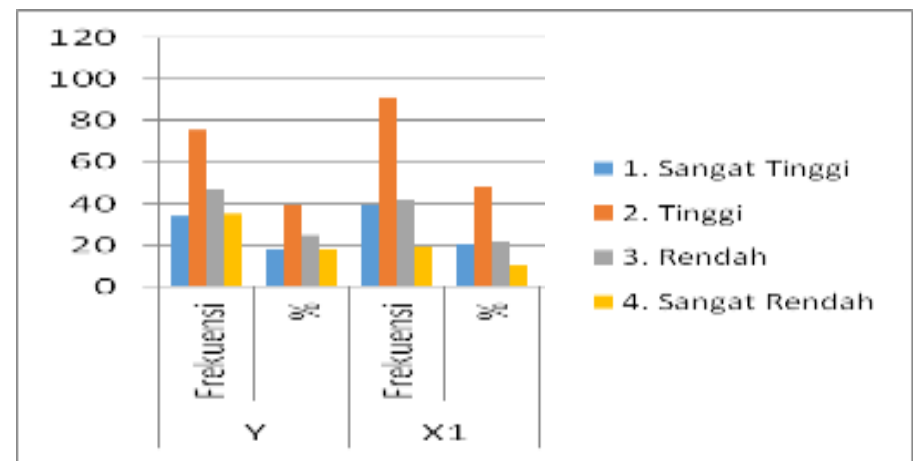

Gambar 1. Distribusi Media Pembelajaran Berbasis Multimedia Interaktif dan Hasil Belajar

Berdasarkan analisis deskriptif dapat pula diketahui pencapaian skor variabel media pembelajaran berbasis multimedia interaktif dengan cara membandingkan skor total yang dicapai dengan skor total tertinggi. Skor total media pembelajaran berbasis multimedia interaktif dapat dilihat pada gambar di bawah ini.

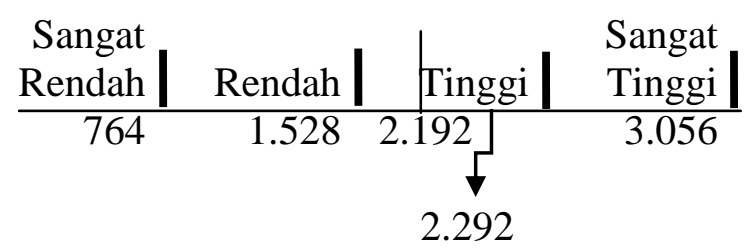

Gambar 2. Hasil pengukuran Teknik Pengukuran Skala Skor Total Media Pembelajaran berbasis Multimedia Interaktif

Varibel media pembelajaran berbasis multimedia interaktif dengan perolehan skor total 2.192, maka skor variabel media pembelajaran berbasis multimedia interaktif cendrung mendekati kategori tinggi dan skor tinggi yang ditetapkan adalah 3.056 sehingga skor variabel media pembelajaran berbasis multimedia interaktif mencapai $71,72 \%$ dari skor tertinggi yang ditetapkan dalam kategori tinggi. 
e-ISSN 2549-7472

Volume 1, Nomor 1, Juni 2017

Mencari kategori variabel hasil belajara sesuai dengan alur tersebut. Tabel skor total hasil belajar adalah sebagai berikut:

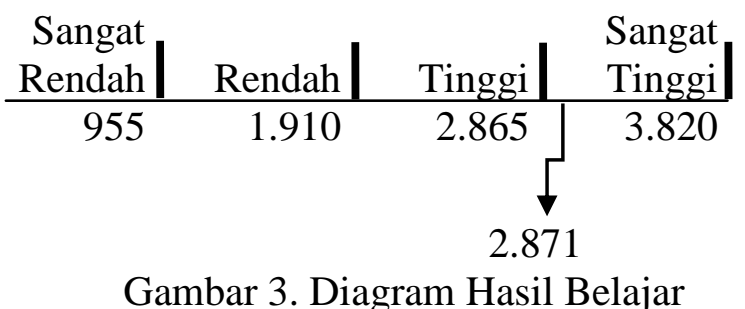

Varibel hasil belajar dengan perolehan skor total 2871, maka skor variabel hasil belajar cendrung mendekati kategori tinggi dan skor tinggi yang ditetapkan adalah 3.820 sehingga skor variabel hasil belajar mencapai $75 \%$ dari sekor tertinggi yang ditetapkan dalam kategori tinggi.

\section{Multimedia Interaktif}

Multimedia interaktif yang digunakan memiliki kelebihan yaitu lebih menarik perhatian, mampu menyajikan peristiwa-peristiwa yang tidak mampu dihadirkan di kelas secara langsung, dan bersifat mandiri. Adapun model-model multimedia interaktif dalam pembelajaran dapat berupa drill, tutorial, simulation, dan games (Rusman, 2005). Sesuai dengan model yang ditampilkan ini searah dengan pendapat Daryanto kelebihan multimedia interaktif adalah sebagai berikut: (1) Memperbesar benda yang sangat kecil dan tidak tampak olehmata, seperti kuman, bakteri, elektrondan lainlain; (2) Memperkecil benda yang sangat besar yang tidak mungkin dihadirkan kesekolah, seperti gajah, rumah, gunung, dan lain-lain; (3) Menyajikan benda atau peristiwa yang kompleks, rumit dan berlangsung cepat atau lambat, seperti sistem tubuh manusia, bekerjanya suatu mesin, beredarnya planet Mars, berkembangnya bung adan lain-lain; (4) Menyajikan benda atau peristiwa yang jauh, seperti bulan, bintang, salju, dan lain-lain; (5) Menyajikan benda atau peristiwa yang berbahaya, seperti letusan gunung berapi, harimau, racun, dan lainlain; (6) Meningkatkan daya tarik dan perhatian siswa (2010: 52). Dengan memberikan media pembelajaran berbais multimedia interaktif diharapkan akan menjadi bagian dari proses pembelajaran. Media pembelajaran berbasis multimedia interaktif harus mampu memberi dukungan bagi terselengggaranya proses komunikasi interaktif antar media dan mahasiswa sebagaimana yang dipersyaratkan dalam proses belajar mengajar (PBM).

\section{Media Pembelajaran}

Rossi dan Breidle (Wina Sanjaya, 2008: 204) mengemukakan bahwa media pembelajaran adalah seluruh alat dan bahan yang dapat dipakai untuk tujuan pendidikan, seperti radio, televisi, buku, koran, majalah, dan sebagainya. Senada dengan Rusman yang menyataka (2012: 159) media adalah pengantar pesan dari pengirim ke penerima pesan, dengan demikian media merupakan wahana penyalur informasi belajar atau penyalur pesan. Dari beberapa pendapat di atas Dapat disimpulkan bahwa media pembelajaran adalah alat bantu dalam melakukan proses pembelajaran baik itu berupa perangkat keras (hardware) dan perangkat lunak (Software).

\section{Interaksi Manusia dan Komputer}

Interaksi Manusia dengan komputer atau human computer intraktion (HCI). HCI adalah disiplin ilmu yang mempelajari hubungan antara manusia dan komputer yang meliputi 
e-ISSN 2549-7472

Volume 1, Nomor 1, Juni 2017

perancangan, evaluasi, dan implementasi antarmuka pengguna komputer agar mudah digunakan oleh manusia (id.m.wikipedia.org). Searah dengan pendapat Sri Erawati (2010: 1) yang menjelaskan interaksi mausia dengan komputer merupakan komunikasi duarah antara pengguna (user) dengan sistem komputer yang saling mendukung untuk mencapai suatu tujuan tertentu.

\section{SIMPULAN}

Penerapan media pembelajaran berbasis multimedia interaktif merupakan salah satu solusi untuk menciptakan pembelajaran yang menarik, inovatif, menantang dan dapat berfikir secara mandiri. Hal tersebut dikarenakan dengan mengunakan multimedia interktif sebagai menyalur informasi, akan dapat merangsang pikiran, perasaan, perhatian dan kemauan sehingga dapat mendorong proses belajar yang lebih interaktif dan komunikatif. Selain itu bentuk-bentuk multimedia interaktif dapat digunakan untuk meningkatkan pengalaman belajar mahasiswa menjadi lebih konkret. Dengan demikian, dapat kita harapkan hasil dan pengalaman belajar menjadi lebih berarti bagi mahasiswa.

\section{REFERENSI}

Daryanto. (2010). Media Pembelajaran (Peranannya Sangat Penting Dalam Mencapai Tujuan Pembelajaran). Yogyakarta: Gava Media.

Mardapi, Djmari. (2007). Teknik Penyusunan instrumen tes dan nontes.Yogyakarta.Mitra Cendikia.

Rusman. (2005). Model-model Multimedia Interaktif Berbasis Komputer. P3MP: UPI.

Rusman. (2012). Belajar dan Pembelajaran Berbasis Komputer. Bandung: Alfabeta.

Sanjaya, W. (2008). Perencanaan dan Desain Sistem Pembelajaran. Jakarta: Kencana Prenada Media Group.

Sugiyono. (2014). Metode Penelitian Kuantitatif, Kualitatif dan R\&D. Bandung: Alfabeta.

Suyanto, M. (2003). Multimedia untuk Meningkatkan Keunggulan Bersaing. Yogyakarta: Andi.

Wagiran. (2014). Metodologi Penelitian Pendidikan: Teori dan Implementasi. Yogyakarta: CV Budi Utama.

Wikipedia. (2017). Interaksi Manusia dengan Komputer. Diunduh Https://id.m.wikipedia.org/wiki/interaksi_manusia-komputer Taggal 21 April 2017. 